Correction

\title{
Correction: Erdin, C. and Ozkaya, G. Turkey's 2023 Energy Strategies and Investment Opportunities for Renewable Energy Sources: Site Selection Based on ELECTRE. Sustainability 2019, 11, 2136
}

\section{Ceren Erdin and Gokhan Ozkaya *(D) \\ Department of Business Administration, Faculty of Economics and Administrative Sciences, Yildiz Technical University, 34220 Istanbul, Turkey; ceren_erdin@yahoo.com \\ * Correspondence: gozkaya@yildiz.edu.tr; Tel.: +9053-6241-5846}

Received: 16 November 2020; Accepted: 17 November 2020; Published: 18 November 2020

The authors would like to make the following corrections to the published paper [1]. The changes are as follows:

(1) Replace Table 1:

Table 1. Energy demand projection (MW) of geographic regions for years 2017-2024 [17].

\begin{tabular}{cccccccc}
\hline Region & $\mathbf{2 0 1 7}$ & $\mathbf{2 0 1 8}$ & $\mathbf{2 0 2 0}$ & $\mathbf{2 0 2 1}$ & $\mathbf{2 0 2 2}$ & $\mathbf{2 0 2 3}$ & $\mathbf{2 0 2 4}$ \\
\hline South Eastern Anatolia & $82,836,159$ & $22,998,808$ & $3,351,502$ & $3,527,482$ & $3,709,637$ & $3,898,641$ & $4,096,695$ \\
\hline Mediterranean & $86,882,584$ & $47,277,290$ & $8,133,181$ & $8,560,235$ & $9,002,277$ & $9,460,938$ & $9,941,56$ \\
\hline Eastern Anatolia & $71,548,67$ & $21,637,484$ & $1,830,07$ & $1,926,163$ & $2,025,628$ & $2,128,833$ & $2,236,979$ \\
\hline Central Anatolia & $86,459,915$ & $26,830,381$ & $7,633,71$ & $8,034,539$ & $8,449,434$ & $8,879,928$ & $9,331,034$ \\
\hline Aegean & $37,522,593$ & $17,954,003$ & $8,889,482$ & $9,356,248$ & $9,839,395$ & $10,340,71$ & $10,866,02$ \\
\hline Marmara & $517,461,27$ & $118,462,650$ & $20,634,06$ & $21,717,51$ & $22,838,98$ & $24,002,61$ & $25,221,96$ \\
\hline Black Sea & $93,671,808$ & $23,882,380$ & $4,338,992$ & $4,566,822$ & $4,802,648$ & $5,047,341$ & $5,303,749$ \\
\hline
\end{tabular}

with

Table 2. Energy demand projection (MW) of geographic regions for years 2017-2024 [17].

\begin{tabular}{ccccccccc}
\hline Region & $\mathbf{2 0 1 7}$ & $\mathbf{2 0 1 8}$ & $\mathbf{2 0 1 9}$ & $\mathbf{2 0 2 0}$ & $\mathbf{2 0 2 1}$ & $\mathbf{2 0 2 2}$ & $\mathbf{2 0 2 3}$ & $\mathbf{2 0 2 4}$ \\
\hline South Eastern Anatolia & $2,836,159$ & $2,998,808$ & $3,171,119$ & $3,351,502$ & $3,527,482$ & $3,709,637$ & $3,898,641$ & $4,096,695$ \\
\hline Mediterranean & $6,882,584$ & $7,277,290$ & $7,695,442$ & $8,133,181$ & $8,560,235$ & $9,002,277$ & $9,460,938$ & 994,156 \\
\hline Eastern Anatolia & 154,867 & $1,637,484$ & $1,731,573$ & 183,007 & $1,926,163$ & $2,025,628$ & $2,128,833$ & $2,236,979$ \\
\hline Central Anatolia & $6,459,915$ & $6,830,381$ & $7,222,853$ & 763,371 & $8,034,539$ & $8,449,434$ & $8,879,928$ & $9,331,034$ \\
\hline Aegean & $7,522,593$ & $7,954,003$ & $8,411,038$ & $8,889,482$ & $9,356,248$ & $9,839,395$ & $1,034,071$ & $1,086,602$ \\
\hline Marmara & $1,746,127$ & $18,462,650$ & $19,523,510$ & $2,063,406$ & $2,171,751$ & $2,283,898$ & $2,400,261$ & $2,522,196$ \\
\hline Black Sea & $3,671,808$ & $3,882,380$ & $4,105,461$ & $4,338,992$ & $4,566,822$ & $4,802,648$ & $5,047,341$ & $5,303,749$
\end{tabular}

The authors and the Editorial Office would like to apologize for any inconvenience caused to the readers by these changes. The changes do not affect the scientific results. The manuscript will be updated and the original will remain online on the article webpage. 


\section{References}

1. Erdin, C.; Ozkaya, G. Turkey's 2023 Energy Strategies and Investment Opportunities for Renewable Energy Sources: Site Selection Based on ELECTRE. Sustainability 2019, 11, 2136. [CrossRef]

Publisher's Note: MDPI stays neutral with regard to jurisdictional claims in published maps and institutional affiliations.

(C) 2020 by the authors. Licensee MDPI, Basel, Switzerland. This article is an open access article distributed under the terms and conditions of the Creative Commons Attribution (CC BY) license (http://creativecommons.org/licenses/by/4.0/). 